Revista lus et Praxis, Año 23, No 2, 2017, pp. 327 - 348

ISSN 0717 - 2877

Universidad de Talca - Facultad de Ciencias Jurídicas y Sociales

La autonomía asociativa de partidos políticos y

sindicatos. Un análisis comparado

José Juan Anzures Gurría

Trabajo recibido el 12 de abril de 2016 y aprobado el 11 de junio de 2016

\title{
La autonomía asociativa de partidos políticos y sindicatos. Un análisis comparado
}

\author{
ASSOCIATIVE AUTONOMY CONCERNING POLTICAL PARTIES AND UNIONS
}

COMPARATIVE ANALYSIS

José Juan Anzures Gurría*

\begin{abstract}
RESUMEN
El derecho fundamental de asociación, reconocido en el art. $9^{\circ}$ de la Constitución mexicana reconoce el derecho de asociarse pacíficamente con cualquier objeto lícito. El contenido de este derecho comprende una dimensión individual y también una dimensión colectiva, que consiste en la autonomía de cada asociación para funcionar libremente sin interferencia alguna por parte de terceros. Esta faceta del derecho fue reconocida en el constitucionalismo de la Segunda Posguerra, pero no en los textos de las constituciones nacientes, sino mediante la interpretación de los Tribunales Constitucionales. La autonomía de cada asociación depende también de cada tipo asociativo, su regulación infraconstitucional no puede entenderse como una violación al ejercicio del derecho, sino como una limitación proporcional.
\end{abstract}

\section{ABSTRACT}

The constitutional right of association is recognized in the art. 9 of the Mexican Constitution and it includes the right to associate peacefully and with lawful purposes with others, but also the right of the association to operate freely without any interference. This aspect of the right was recognized after de World War Second, not in the constitutions, but in the Constituional Courts interpretations of this right. The autonomy of each association depends on its type, which is regulated by secondary norms. The regulation of different kinds of association is not a violation of its autonomy. Political parties and Unions are more consticted in its autonomy right than others assocations due to its public and social relevance.

\section{PALABRAS CLAVES}

Derecho de asociación, autonomía asociativa, partidos políticos, sindicatos

KEY WORDS

Right of association, association autonomy, Politcal Parties, Unions

\footnotetext{
* Licenciado en Derecho por el Instituto Tecnológico y de Estudios Superiores de Monterrey, Campus Ciudad de México. Maestría en Derecho de la Globalización y la Integración Social por la Universidad de Navarra. Estancia de investigación en la Universidad de Münster, en Münster, Alemania. Doctor en Derecho por la Universidad de Navarra. Ha impartido diversas clases en licenciatura, maestría y doctorado. Ha publicado distintos libros y artículos doctrinales. Actualmente, es Director del Departamento de Derecho y Relaciones Internacionales en el Tecnológico de Monterrey Campus Puebla y miembro del Sistema Nacional de Investigadores Nivel I. Correo electrónico anzuresgurria@itesm.mx.
} 


\section{Introducción}

El derecho fundamental de asociación protege no solo las actividades individuales de cada persona, sino también a las asociaciones que nacen del ejercicio individual del derecho. En este sentido, todo tipo de asociación tiene la libertad de organizarse libremente sin interferencia alguna por parte de terceros, especialmente por parte del Estado.

Cabe destacar, en primer lugar, que el derecho de asociación no se reconoció en las primeras declaraciones del constitucionalismo liberal y no fue sino hasta bien entrado el siglo XIX que algunos textos constitucionales lo empezaron a reconocer, sobre todo en lo referente a los sindicatos y partidos políticos, y apenas a principio del siglo XX el derecho de asociación se reconoce con plenitud en las Constituciones del mundo occidental, aunque siempre en su dimensión individual, es decir, en la facultad que tiene cada persona para asociarse con otros con la intención de conseguir un fin común.

La asociación como objeto de protección del mismo derecho de asociación se reconoció después de la Segunda Guerra Mundial, pero no tanto por las constituciones de los distintos países, sino sobre todo por sus Tribunales Constitucionales, que al conocer casos que implicaban el derecho de asociación interpretaban que este protegía a la misma asociación. Así, el Tribunal de Karlsruhe fue pionero en este sentido e inmediatamente seguido por el Tribunal Constitucional de Italia y España.

En México, el derecho de asociación se reconoce en el art. $9^{\circ}$ de nuestra Constitución Política, pero con casi los mismos términos con que se reconoció en el art. $9^{\circ}$ de la Constitución de 1857, por lo que guarda una marcada concepción liberal y naturalmente no hace referencia alguna a la protección de las asociaciones. No obstante, es de destacar que nuestro texto constitucional (si bien reformado) sí habla de la protección de los partidos políticos y de los sindicatos.

Ahora bien, reconocer que el derecho fundamental de asociación protege también a las asociaciones significa que se les reconoce una libertad de autoorganización y aunque siempre ha existido esta facultad, lo importante de lo que aquí se expone es que esta libertad se encuentra constitucionalmente protegida. Aunado a lo anterior vale destacar que esta libertad no es igual para todo tipo de asociación, pues aunque cada una tiene la facultad de organizarse como desee, cada asociación debe observar la regulación que el legislador haya hecho de cada tipo y ceñirse a estos requisitos legales según el tipo asociativo del cual se trate.

En este sentido, existen asociaciones que a pesar de ser privadas tienen una relevancia pública, como es el caso de los partidos políticos y los sindicatos, y es debido a su relevancia pública, a su relevancia para el Estado constitucional 
y democrático de Derecho que su organización interna se encontrará más regulada o más restringida que una asociación que no tenga esta interferencia directa en la construcción y consolidación democráticas.

\section{Nacimiento y reconocimiento de la autonomía asociativa}

El derecho fundamental de asociación ha consistido desde sus orígenes en la facultad individual de cada persona para unirse con otras de manera permanente para la consecución de un fin legal determinado sin prohibiciones preventivas ni arbitrarias por parte del Estado ${ }^{1}$; pero el ejercicio del derecho de asociación quedaría incompleto si una vez creada una asociación, esta no pudiera organizarse y actuar libremente.

La autonomía que tiene toda asociación para actuar sin injerencia alguna por parte de terceros se ha denominado en la doctrina constitucional española y alemana como la dimensión colectiva del derecho de asociación, que es reconocida, precisamente, después de la Segunda Guerra Mundial por el Tribunal Constitucional del país germano, que señaló que el ámbito de protección del art. $9^{\circ}$ de la Ley Fundamental de Bonn se refiere no solo a la facultad individual para crear asociaciones, sino también a la misma asociación.

En su sentencia de 18 de octubre de $1961^{2}$ el máximo Tribunal alemán señaló que el ámbito de libertad que debe reconocérseles a las asociaciones se concretiza en su derecho a constituirse y existir (Recht auf Enstehen und Bestehen) ${ }^{3}$ sin interferencia del poder público, y poco tiempo después señaló, en su resolución de 24 de febrero de $1971^{4}$, que la protección que se dispensa a la asociación en sí misma consiste en reconocerle una zona nuclear o zona núcleo libre de cualquier interferencia estatal para que pueda tomar las decisiones pertinentes respecto a su existencia y su actividades (Kernbereich des Vereinsbestandes und der Vereinstätigkeit). Esta zona nuclear, dice más adelante la sentencia, así como el derecho que tienen las asociaciones a nacer $y$ existir (Recht auf Entstehen und Bestehen) forman parte del contenido esencial del derecho de asociación consagrado en el art. 9.1 LFB; en consecuencia, el Tribunal Constitucional alemán afirmó que cualquier regulación tendente a

\footnotetext{
${ }^{1}$ SChmidt (1983), p. 64; en el mismo sentido, Merten (2009), p. 1046, señala que históricamente la lucha por la libertad de asociación ha sido una lucha contra la prohibición de las asociaciones.

${ }^{2}$ BVerfGE 13, 174, 175.

${ }^{3}$ BVerfGE 3, 383, 391; 6, 273, 277; 13, 174, 175.

${ }^{4}$ BVerfGE 30, 227, 441.
} 
limitar esta autodeterminación de la asociación es una violación al contenido esencial del derecho de asociación ${ }^{5}$.

El reconocimiento más contundente por parte del Tribunal de Karlsruhe respecto de la protección de la asociación se contiene en su sentencia de 1 de marzo de $1979^{6}$, en la que señaló que el art. $9^{\circ}$ LFB protege tanto a los socios como a la asociación la libre autodeterminación respecto de su organización, el procedimiento en la toma de decisiones y la gestión de sus negocios, afirmando que no se puede hablar de una verdadera libertad de asociación si no se reconoce la plena autodeterminación de la asociación; atentar contra este principio -señala la sentencia- sería ir en contra de la finalidad protectora del art. $9^{\circ} \mathrm{LFB}^{7}$.

En España, la mayoría de las leyes que regularon el derecho de asociación durante el siglo XIX contemplaron un gran intervencionismo por parte del Estado en el seno de las asociaciones ${ }^{8}$. Durante el régimen franquista la intromisión fue aún mayor, sobre todo respecto de aquellas asociaciones de carácter político, ya que se consideraban una amenaza para la estabilidad del

\footnotetext{
${ }^{5}$ BVerfGE 50, 290, 354.

${ }^{6}$ BverfGE 50, 290, 354 y 367.

${ }^{7}$ BVerfGE 50, 290, 354 y 367.
}

${ }^{8}$ Así, la ley de 1887 permitía que la autoridad gubernativa penetrase en cualquier momento en el domicilio de una asociación y en el local en que celebrase sus reuniones, pudiendo mandar a suspender en el acto toda sesión o reunión en que se acordase cometer algunas de las conductas contenidas como delitos en el Código Penal. Esta ley también contemplaba la posibilidad de que el gobernador de la provincia pudiese acordar la suspensión de las funciones de cualquier asociación cuando de sus acuerdos o de los actos de sus socios resultasen razones bastantes para estimar que podían considerarse como ilícitos o que se habían cometido delitos y permitía también que la autoridad judicial decretase la suspensión de las funciones de las asociaciones desde el instante mismo en que se dictase auto de procesamiento por delito que pudiese dar lugar a su eventual disolución. La ley exigía, además, que toda asociación llevara y exhibiera ante la autoridad, cuando esta lo exigiese, el registro de los nombres y el domicilio de todos los asociados, en especial de aquellos que ejerciesen cargos de administración, gobierno o representación. El nombramiento o elección de estos últimos debía notificarse al gobernador de la provincia por escrito dentro de los cinco días siguientes a que tuviese lugar. También se establecía la obligación de llevar uno o varios libros de contabilidad, en los que, bajo la responsabilidad de los que ejercían cargos administrativos o directivos, debían figurar todos los ingresos y gastos de la asociación, expresando inequívocamente la procedencia de estos y la inversión de los mismos, y anualmente debía remitirse, además, un balance general al registro de la provincia. El incumplimiento de estas obligaciones, según el art. 10 de la ley, se castigaba por el gobernador de la provincia con una multa de 50 a 150 pesetas para cada uno de los asociados que ejercieran estas funciones, sin perjuicio de las responsabilidades civiles o criminales que resultasen pertinentes. Respecto a las asociaciones que recaudasen o distribuyesen fondos con destino al socorro o auxilio de los asociados, a fines de beneficencia, instrucción u otros análogos, esta ley establecía la obligación de formalizar semestralmente las cuentas de sus ingresos y sus gastos, poniéndolas de manifiesto a sus socios y entregando un ejemplar de ellas al gobierno de la provincia dentro de los cinco días posteriores a su formalización. Tomado de Velloso Jiménez (1982), pp. 33 y ss. 
régimen. Así, la Ley Reguladora del Derecho de Asociación de 1964 fue una norma sumamente invasiva del régimen interior de las asociaciones ${ }^{9}$; si bien podría parecer que concedía cierta autonomía en la autodeterminación de su funcionamiento interno, al señalar que este se determinaba en sus propios estatutos y en los acuerdos válidamente aceptados en la Asamblea General y en los Órganos Directivos, los controles por parte de la Administración pública se incrementaban a lo largo de su articulado llegando a una intervención administrativa que llegaba a ser asfixiante ${ }^{10}$.

Fue con la Constitución de 1978 cuando se reconoció que las asociaciones en sí mismas se encuentran protegidas por la libertad de asociación. Del análisis de la Carta Magna de España se advierte que los artículos $6^{\circ}$ y $7^{\circ}$, que reconocen a los partidos políticos, sindicatos y asociaciones empresariales, protegen a estos tipos asociativos al señalar que su creación y el ejercicio de sus actividades son libres dentro del respeto a la Constitución y a la Ley, y aunque el art. 22 CE no contiene de manera expresa este reconocimiento, el Tribunal Constitucional de este país ha admitido en varias ocasiones que el derecho de asociación protege también al ente creado del derecho individual.

Una de las primeras sentencias en las que el máximo Tribunal de España se manifestó respecto de esta cuestión, si bien en el ámbito sindical, fue en su sentencia 70/1982, de 29 de noviembre, en la que señaló que la libertad de sindicación comprende no solo el derecho de los individuos a fundar sindicatos y a afiliarse a los de su elección, sino también el derecho de los sindicatos a realizar las funciones que de hecho es dable esperar (FJ $3^{\circ}$.). En la STC 85/1986, de 25 de junio, el mismo Tribunal señaló, refiriéndose ahora a los partidos políticos, que en tanto estos entes son asociaciones, se les debe permitir y asegurar el menor grado de control e intervención por parte del Estado, con lo que "... se reconoce y legitima la existencia de los partidos y se garantiza su existencia y su subsistencia" (FJ $2^{\circ}$.). Pero el leading case en esta materia ha sido sin duda la STC 218/1988, de 22 noviembre, en la que el Tribunal Constitucional calificó de "indiscutible premisa" que el derecho de asociación, reconocido en el art. 22

\footnotetext{
${ }^{9}$ La ley obligaba a las asociaciones a establecer como mínimo dos órganos: la Asamblea General y la Junta Directiva, a llevar ficheros y libros de contabilidad y a delimitar la forma en que habrían de recibirse ingresos a título gratuito por donaciones, y en todos estos casos, la autoridad gubernativa tenía que ser notificada o tenía potestad para intervenir y revisar, lo que en palabras de PeLAYo Olmedo (2007), p. 25, "se convierte en un nuevo resorte de control". Esta ley preveía también la necesidad de comunicar al Gobernador de la provincia, con 72 horas de antelación, la fecha y hora en que habrían de celebrarse las sesiones generales (art. 7.2 de la ley 191/1964) y permitía, además, a la autoridad gubernativa tener acceso, mediante representantes especialmente designados, al local donde se celebrasen las reuniones, así como a los libros y documentos que llevaran las asociaciones.
}

${ }^{10}$ Fernández SeGado (1986), p. 710. 
CE, "comprende no sólo el derecho a asociarse, sino también el de establecer la propia organización del ente creado por el acto asociativo..." (FJ $1^{\circ}$. $^{11}$.

En su sentencia 96/1994, de 21 de marzo, el Tribunal Constitucional español reconoció otra vez que el derecho de asociación comprende también la autoorganización del ente creado y que esta facultad se extiende a dotarse de sus propios estatutos y establecer en ellos las causas de expulsión de los socios. En su posterior sentencia 104/1999, de 14 de junio, el máximo Tribunal reconoció además que el derecho que tienen los ciudadanos para fundar y participar en asociaciones se plasma también en la "disponibilidad de organizarse libremente..." (FJ 2º.); y en la STC 210/2001 señaló que no existe obstáculo alguno "para que una asociación, en cuanto persona jurídica distinta de las personas que son sus asociados $-y$, por tanto, centro autónomo de relaciones y consecuencias jurídicas- pueda invocar en su favor el derecho que el art. 22 CE reconoce ${ }^{\prime 12}$. También en el ATC 254/2001, de 20 de septiembre, el Tribunal reconoció que las asociaciones son libres en el ejercicio de su autonomía y este ejercicio conlleva la potestad de autoorganización, libre en principio de las injerencias del poder público, aunque este derecho, señala el mismo Tribunal, tendrá como límites el respeto a los demás derechos fundamentales, valores, bienes o intereses constitucionalmente protegidos ${ }^{13}$.

\footnotetext{
${ }^{11}$ En el caso citado, la asociación Círculo Mercantil, un casino de la ciudad de la Línea de la Concepción en Cádiz, acordó expulsar a tres de sus miembros por considerar que habían cometido una falta grave de acuerdo con lo establecido en sus propios estatutos. Los expulsados recurrieron la decisión de la asociación ante el Juzgado de Distrito, que dictó sentencia desestimatoria, misma que fue apelada ante la Audiencia Provincial de Cádiz, que consideró estimada la demanda original y condenó a la asociación a readmitir a los socios. Ante esta resolución, la asociación interpuso recurso de amparo ante el Tribunal Constitucional entendiendo que se había vulnerado su derecho fundamental de asociación, en tanto su facultad autoorganizativa. El Tribunal Constitucional admitió el recurso, y al resolver reconoció que la sentencia impugnada por la asociación vulneraba su derecho de autoorganización, toda vez que el juez entró a enjuiciar el acierto con que esos motivos habían sido interpretados por los órganos rectores de la asociación, sustituyendo la valoración que la asociación había hecho de ellos por la del propio Tribunal.
}

${ }^{12}$ Véase también la STC 185/1993, de 31 de mayo.

${ }^{13}$ De igual forma, el Tribunal Supremo español reconoció que el art. 22 CE protege tanto al individuo como a la misma asociación. En su sentencia de 30 de junio de 1994 señaló que no puede entenderse que el derecho de asociación consista en exclusiva en el derecho a constituir una asociación, marginando del mismo la propia dinámica ulterior de la asociación ya constituida y, más adelante, volverá a decir que "el derecho fundamental de asociación no puede restringirse constitucionalmente al sólo aspecto de la creación de la asociación, (...) pues no hay dificultad, ni lógica ni jurídica, para que, una vez creada la asociación, otros contenidos de ese derecho pueden corresponder a la titularidad de la asociación misma". Y en su sentencia de 19 de julio de 2004 (Sala de lo Civil), en su FD $1^{\circ}$ dirá que el derecho de asociación que reconoce la Constitución en su art. 22 CE tiene un contenido complejo, en la dimensión que incumbe al propio ente, dicho derecho, reza la sentencia, "comprende su capacidad de auto organizarse libremente, esto es, la facultad de los asociados de 
En México, el derecho de asociación tampoco fue reconocido en los primeros textos constitucionales. La Constitución de Cádiz de 1812, la Constitución de Apatzingán de 1814, la Constitución de 1824 y las Siete Leyes de 1836 omitieron en su texto el derecho de asociación y en muchas ocasiones lo llegaron a prohibir. No fue sino con la Constitución de 1857 que se reconoció expresamente el derecho de asamblea en su art. $9^{\circ}$, que fue recogido en los mismos términos en el también art. $9^{\circ}$ de la Constitución de 1917, al señalar que "[n]o se podrá coartar el derecho de asociarse o reunirse pacíficamente con cualquier objeto lícito"14, pero no se hace mención alguna a la asociación o a la libertad de las asociaciones para funcionar sin interferencia alguna por parte del Estado.

No obstante lo anterior, al reconocer la Constitución mexicana determinados tipos asociativos, se reconoce a estos cierta libertad. Así, los arts. 41 base I, párrafo tercero, y 116 fr. IV, inciso f), prevén la facultad de autoorganización y autodeterminación de los partidos políticos, en virtud de las cuales las autoridades solo pueden intervenir en la vida interna de dichos institutos en los términos establecidos por el propio Ordenamiento Fundamental y las leyes ${ }^{15}$, mientras que el art. 130 CPEUM señala en su inciso a) que "las autoridades no intervendrán en la vida interna de las asociaciones religiosas".

En el ámbito jurisprudencial los Tribunales se han mostrado tímidos al reconocer la libertad de las asociaciones como ámbito constitucionalmente

organizar y determinar el funcionamiento interno de la asociación sin injerencias públicas...". Véase también la STS 1068/2008, de 7 de noviembre, FD $1^{\circ}$. (Sala de lo Civil, Sección $1^{\mathrm{a}}$.). El artículo 22 de la Constitución española dice a la letra: "Se reconoce el derecho de asociación. 2. Las asociaciones que persigan fines o utilicen medios tipificados como delito son ilegales. 3. Las asociaciones constituidas al amparo de este artículo deberán inscribirse en un registro a los solos efectos de publicidad. 4. Las asociaciones sólo podrán ser disueltas o suspendidas en sus actividades en virtud de resolución judicial motivada. 5. Se prohíben las asociaciones secretas y las de carácter paramilitar".

${ }^{14}$ El texto del art. $9^{\circ}$. de la Constitución de 1857 rezaba: "[...] a nadie se le puede coartar el derecho de asociarse o de reunirse pacíficamente con cualquier objeto lícito; pero solamente los ciudadanos de la República lo pueden hacer para tomar parte en los asuntos políticos del país...". El actual artículo $9^{\circ}$ de la Constitución de 1917 señala: "No se podrá coartar el derecho de asociarse o reunirse pacíficamente con cualquier objeto lícito; pero solamente los ciudadanos de la República podrán hacerlo para tomar parte en los asuntos políticos del país. Ninguna reunión armada, tiene derecho de deliberar. No se considerará ilegal, y no podrá ser disuelta una asamblea o reunión que tenga por objeto hacer una petición o presentar una protesta por algún acto, a una autoridad, si no se profieren injurias contra ésta, ni se hiciere uso de violencias o amenazas para intimidarla u obligarla a resolver en el sentido que se desee".

${ }^{15}$ Art. 41, I, tercer párrafo: "Las autoridades electorales solamente podrán intervenir en los asuntos internos de los partidos políticos en los términos que señalen esta Constitución y la ley". Art. 116 fr. IV: "Las autoridades electorales solamente puedan intervenir en los asuntos internos de los partidos en los términos que expresamente señalen". 
protegido por el derecho fundamental de asociación, aunque pueden encontrarse algunas Tesis que hacen algún tipo de reconocimiento en este sentido, sobre todo cuando se trata de sindicatos. Una interesante Tesis de la $7^{\text {a }}$ época de nuestra SCJN señaló que la autonomía de la asociación (refiriéndose a los sindicatos) "... se interpreta como la capacidad de organización, de creación del estatuto al que habrán de constreñirse sus socios, de administración de su patrimonio, de funcionamiento y de actividad externa para el logro de sus fines inmediatos y mediatos" 16 . En otra sentencia, ya de la 9a época, del 27 de mayo de 1999, al resolver varios juicios de amparo, la SCJN emitió la Tesis jurisprudencial $N^{\circ} 43 / 1999$, en la que señaló que el derecho de sindicación de los trabajadores comprende un derecho a asociarse y "un derecho colectivo, una vez que el sindicato adquiere existencia y personalidad propias"; inmediatamente después la resolución explica que la dimensión individual comprende 1) un aspecto positivo, que consiste en la facultad del trabajador para ingresar a un sindicato ya integrado o constituir uno nuevo; 2) un aspecto negativo, que implica la posibilidad de no ingresar a un sindicato determinado y la de no afiliarse a sindicato alguno; y 3 ) la libertad de separación o renuncia de formar parte de la asociación, y deja en el olvido el aspecto colectivo que había mencionado líneas atrás. Hubiera sido conveniente que, si ya se había reconocido una dimensión colectiva del derecho de sindicación, se hubiera

16 [TA]; 7a Época; 4a Sala; S.J.F.; Volumen 115-120, Quinta Parte; p. 77. Preferencia, derechos de, por antigüedad, y autonomía sindical. Para la concesión o negativa del amparo es importante analizar lo que significa la autonomía sindical, relacionándola con el derecho de ocupación por causa de antigüedad. Es principio del derecho mexicano del trabajo, conforme a la fracción XVI del artículo 123 constitucional y a los artículos 356, 357, 359, 366 y 368 de su ley reglamentaria, "el de la autonomía de la asociación, misma que se interpreta como la capacidad de organización, de creación del estatuto al que habrán de constreñirse sus socios, de administración de su patrimonio, de funcionamiento y de actividad externa para el logro de sus fines inmediatos y mediatos. Conforme al régimen jurídico existente, tal autonomía es operativa y en nada se afecta por las limitaciones que le imponen los derechos en protección a los trabajadores que establece la legislación, o sean, los que contiene el orden jurídico imperante, tal y como lo es el de ocupación, condicionante de la sobrevivencia de las personas y que en el ámbito del trabajo se consagra mediante las preferencias a que se refiere el artículo 154 del código laboral vigente. Expresando en otras palabras, en nada se afecta la autonomía sindical o desmerece la facultad, libre de los socios de un sindicato para dictarse su ley suprema, si en cuenta toman la prevalencia de los derechos que reconoce el orden jurídico en favor de los propios trabajadores, cuya custodia y defensa corresponde a las organizaciones sindicales...". Cuarta Sala. Amparo directo 1774/78. Sección 29 del Sindicato de Trabajadores Petroleros de la República Mexicana. 7 de agosto de 1978. Unanimidad de cuatro votos. Ponente: María Cristina Salmorán de Tamayo. Secretario: Moisés Duarte Aguíniga. Séptima Época, Quinta Parte: Volumen 87, página 22. Amparo directo 2934/75. Guadalupe Aguirre Castellanos. 19 de marzo de 1976. Unanimidad de cuatro votos. Ponente: Juan Moisés Calleja García. Secretario: Moisés Duarte Aguíñiga. Genealogía: Informe 1976, Segunda Parte, Cuarta Sala, tesis 40, página 25. 
explicado en qué consistía esta ${ }^{17}$. Más reciente, en 2010, la SCJN reconoció en su Tesis jurisprudencial 58/2010, en este caso refiriéndose a los partidos políticos, que estos tienen una garantía institucional de autoorganización y autodeterminación que se desprende del art. 41, base I, párrafo tercero y 116, fr. IV, inciso f), de la CPEUM ${ }^{18}$, y que la misma no se vulnera por la regulación de algunos aspectos que las leyes correspondientes determinen.

En el ámbito de la legislación infraconstitucional se ha reconocido también que las asociaciones tienen libertad de funcionamiento. El art. 22 fr. 5. del antiguo Cofipe ya señalaba que "los partidos políticos se regirán internamente por sus documentos básicos, tendrán la libertad de organizarse y determinarse de conformidad con las normas establecidas en el presente Código y las que, conforme al mismo, establezcan sus estatutos"; con la reforma electoral de 2014 la Ley General de Partidos Políticos también reconoce en su art. 23.1 inciso " $C^{\text {" }}$ que son derechos de los partidos políticos "gozar de facultades para regular su vida interna y determinar su organización interior y los procedimientos correspondientes", y en su art. 34 señala que "[p] ara los efectos de lo dispuesto en el penúltimo párrafo de la Base I del artículo 41 de la Constitución, los asuntos internos de los partidos políticos comprenden el conjunto de actos y procedimientos relativos a su organización y funcionamiento, con base en las

\footnotetext{
${ }^{17}$ Sindicación única. Las leyes o estatutos que la prevén violan la libertad sindical consagrada en el artículo 123, apartado 'B', fracción X, constitucional. El artículo 123 constitucional consagra la libertad sindical con un sentido pleno de universalidad, partiendo del derecho personal de cada trabajador a asociarse y reconociendo un derecho colectivo, una vez que el sindicato adquiere existencia y personalidad propias. Dicha libertad debe entenderse en sus tres aspectos fundamentales: 1 . Un aspecto positivo que consiste en la facultad del trabajador para ingresar a un sindicato ya integrado o constituir uno nuevo; 2 . Un aspecto negativo, que implica la posibilidad de no ingresar a un sindicato determinado y la de no afiliarse a sindicato alguno; y 3. La libertad de separación o renuncia de formar parte de la asociación.

18 [J]; 9a Época; Pleno; S.J.F. y su Gaceta; Tomo XXXI, abril de 2010; p. 1567. "Instituciones y procedimientos electorales del estado de Baja California. Los artículos 216, párrafo segundo, 221, fracción IV, párrafo tercero y 238, fracción III, incisos c) y d), de la ley relativa, al condicionar las precampañas a la existencia de dos o más precandidatos, no transgreden las garantías institucionales de auto-organización y auto-determinación de los partidos políticos, ni el principio de equidad en la contienda. Los artículos 41, base I, párrafo tercero y 116, fracción IV, inciso f), de la Constitución Política de los Estados Unidos Mexicanos prevén las garantías institucionales de auto-organización y auto-determinación de los partidos políticos, en virtud de las cuales las autoridades sólo pueden intervenir en la vida interna de dichos institutos en los términos establecidos por el propio Ordenamiento Fundamental y las leyes, así como el principio de equidad en la contienda, conforme al cual se garantiza que las condiciones materiales y jurídicas en la contienda electoral no favorezcan a alguno de los participantes...". Pleno. Acción de inconstitucionalidad 85/2009. Partido Político Convergencia. 11 de febrero de 2010. Once votos. Ponente: Juan N. Silva Meza. Secretario: José Francisco Castellanos Madrazo. El Tribunal Pleno, el doce de abril en curso, aprobó, con el número 58/2010, la tesis jurisprudencial que antecede. México, Distrito Federal, a doce de abril de dos mil diez.
} 
disposiciones previstas en la Constitución, en esta Ley, así como en su respectivo Estatuto y reglamentos que aprueben sus órganos de dirección".

Por su parte, el art. 357 de la Ley Federal del Trabajo (LFT) señala que "[c] ualquier injerencia indebida (en los sindicatos) será sancionada en los términos que disponga la Ley", y en el art. 359 señala que "los sindicatos tienen derecho a redactar sus estatutos y reglamentos, elegir libremente a sus representantes, organizar su administración y sus actividades y formular su programa de acción"; también el Código Civil Federal señala que las personas morales obran y se obligan por medio de los órganos que las representan, sea por disposición de la ley o conforme a las disposiciones relativas de sus escrituras constitutivas y de sus estatutos (arts. 27 y 28), y más adelante, al regular las asociaciones civiles, el Código señala que estas se regirán por sus estatutos (art. 2673).

En fin, no tratamos de interpretar el texto constitucional a partir de las leyes, sino dejar en claro que la libertad de funcionamiento de las asociaciones, cualquiera que sea el tipo, es una cuestión reconocida y legalmente protegida. Lo que tratamos de aclarar aquí es que este ámbito de libertad de la asociación no es solo un derecho legal, sino además y sobre todo, un derecho constitucional, una manifestación del derecho fundamental de asociación, pues es innegable que el ámbito de protección que dispensa la libertad de asociación comprende no solo al sujeto individualmente considerado, sino también al ente que nace del ejercicio de dicho derecho, y es que el derecho de asociación debe entenderse como un triángulo indisociable conformado por la formación de la asociación, su vida interna y sus acciones externas, y si la vida interna de las asociaciones no fuese libre perderían su misión y morirían de inanición ${ }^{19}$. Por lo demás, reconocer la libertad de crear asociaciones pero no dispensar la debida protección a estas sería un sinsentido ${ }^{20}$.

\section{Los tipos asociativos como límites a la autonomía asociativa}

La autonomía de las asociaciones, de la que venimos hablando, se ve limitada por el tipo asociativo del que se trate, o bien por alguna condición particular que esta ostente, y es que resulta lógico que la asociación que se someta a un tipo determinado observe las disposiciones legales que para ella existan, lo que no significa la conculcación de su autonomía por parte del legislador, sino la configuración del tipo asociativo atendiendo a su naturaleza y a sus fines. Las asociaciones privadas que, quizá debido a su propia naturaleza, se encuentran

\footnotetext{
${ }^{19}$ Así, De la Cueva (2002), pp. 285 y 286. Refiriéndose a los sindicatos.

20 "Una libertad que no comprende las actividades propias de su ejercicio es como una cáscara vacía de contenido", dice GASTROPH (1979), p. 65.
} 
en un régimen legal más limitativo de su propia autonomía son aquellas que tienen una relevancia (no naturaleza) pública y también social; es el caso de los partidos políticos, sindicatos y asociaciones monopolistas o con relevancia en un determinado sector.

\subsection{Partidos políticos}

Los partidos políticos son asociaciones que desempeñan un papel primordial dentro del sistema democrático de nuestro país; detentan el monopolio de la participación política, en tanto representan la única oportunidad real que tiene el ciudadano común de influir en las decisiones políticas; ocupan las instituciones públicas y se financian con fondos públicos. El art. 41 CPEUM reconoce que los partidos políticos son vehículos para que los ciudadanos puedan tener acceso a las funciones representativas, por lo que el derecho de asociación política que subyace a la creación de partidos políticos (como los partidos mismos) resulta de gran trascendencia para nuestro Estado democrático. Así lo entendió el Tribunal Electoral del Poder Judicial de la Federación al señalar que "la libertad de asociación, que subyace a ese derecho, constituye una conditio sine qua non de todo Estado constitucional democrático de derecho, pues, sin la existencia de este derecho fundamental o la falta de garantías constitucionales que lo tutelen, no sólo se impediría la formación de partidos políticos y de asociaciones de diversos signos ideológicos, sino que el mismo principio constitucional de sufragio universal (...) quedaría socavado" ${ }^{21}$.

\footnotetext{
${ }^{21}$ Derecho de asociación en materia político-electoral. Base de la formación de los partidos políticos y agrupaciones políticas. El derecho de asociación en materia político-electoral es un derecho fundamental consagrado en el artículo 35, fracción III, de la Constitución Política de los Estados Unidos Mexicanos que propicia el pluralismo político y la participación de la ciudadanía en la formación del gobierno. La libertad de asociación, que subyace a ese derecho, constituye una conditio sine qua non de todo Estado constitucional democrático de derecho, pues, sin la existencia de este derecho fundamental o la falta de garantías constitucionales que lo tutelen, no sólo se impediría la formación de partidos políticos y de asociaciones de diversos signos ideológicos, sino que el mismo principio constitucional de sufragio universal, establecido en forma expresa en el artículo 41, fracción I, párrafo segundo, de la Constitución Federal, quedaría socavado; por lo tanto, el derecho de asociación en materia político-electoral está en la base de la formación de los partidos políticos y asociaciones políticas. Sobre el particular, es necesario dejar establecido que todo ciudadano mexicano tiene derecho a asociarse individual y libremente para tomar parte en forma pacífica en los asuntos políticos del país; específicamente, es derecho de los ciudadanos mexicanos constituir partidos políticos nacionales y agrupaciones políticas, en conformidad con lo dispuesto en los artículos 90; 35, fracción III; 41, fracciones I, párrafo segundo in fine, y IV, y 99, fracción V, de la Constitución Federal, así como 5º párrafo 1, del Código Federal de Instituciones y Procedimientos Electorales. Así, en ejercicio del derecho de asociación en materia político-electoral, los ciudadanos pueden formar partidos políticos y agrupaciones políticas, cumpliendo con los requisitos que se establecen en la ley. El ejercicio de la libertad de asociación en materia política prevista en el artículo $9^{\circ}$ constitucional está sujeta a varias limitaciones y una condicionante: las primeras están dadas
} 
Debido precisamente a la importancia que revisten los partidos políticos para la consolidación y mantenimiento del Estado democrático y constitucional de Derecho, es que estos entes han de observar ciertas limitaciones en su régimen interior. Así lo explica también el Tribunal Electoral del Poder Judicial de la Federación al señalar que "si el ejercicio de la libertad de afiliación se realiza a través de los institutos políticos, debe cumplirse con las formas específicas reguladas por el legislador para permitir su intervención en el proceso electoral"22.

por el hecho de que su ejercicio sea pacífico y con un objeto lícito, mientras que la última circunscribe su realización a los sujetos que tengan la calidad de ciudadanos mexicanos, lo cual es acorde con lo previsto en el artículo 33 de la Constitución Federal. Asimismo, si el ejercicio de esa libertad política se realiza a través de los partidos políticos, debe cumplirse con las formas específicas que se regulen legalmente para permitir su intervención en el proceso electoral. Tercera Época: Juicio para la protección de los derechos político-electorales del ciudadano. SUP-JDC-117/2001.- José Luis Amador Hurtado.30 de enero de 2002.- Mayoría de cinco votos.- Los Magistrados Eloy Fuentes Cerda y Alfonsina Berta Navarro Hidalgo votaron porque se confirmara la resolución impugnada, al considerar que la parte actora no comprobó el hecho fundatorio de sus pretensiones jurídicas, omitiendo, en consecuencia, pronunciarse sobre la cuestión jurídica que aborda la presente tesis. Juicio para la protección de los derechos político-electorales del ciudadano. SUP-JDC-127/2001.- Sandra Rosario Ortiz Noyola.- 30 de enero de 2002.- Mayoría de cinco votos.- Los Magistrados Eloy Fuentes Cerda y Alfonsina Berta Navarro Hidalgo votaron porque se confirmara la resolución impugnada, al considerar que la parte actora no comprobó el hecho fundatorio de sus pretensiones jurídicas, omitiendo, en consecuencia, pronunciarse sobre la cuestión jurídica que aborda la presente tesis. Juicio para la protección de los derechos político-electorales del ciudadano. SUP-JDC-128/2001.- Dora Soledad Jácome Miranda.- 30 de enero de 2002.- Mayoría de cinco votos.- Los Magistrados Eloy Fuentes Cerda y Alfonsina Berta Navarro Hidalgo votaron porque se confirmara la resolución impugnada, al considerar que la parte actora no comprobó el hecho fundatorio de sus pretensiones jurídicas, omitiendo, en consecuencia, pronunciarse sobre la cuestión jurídica que aborda la presente tesis. Sala Superior, tesis S3ELJ 25/2002.

${ }^{22}$ Derecho de afiliación en materia político-electoral. Contenido y alcances. El derecho de afiliación político-electoral establecido en el artículo 41, fracción I, párrafo segundo, in fine, de la Constitución Política de los Estados Unidos Mexicanos, en relación con lo dispuesto en el artículo 5º párrafos 1 y 3 , del Código Federal de Instituciones y Procedimientos Electorales, es un derecho fundamental con un contenido normativo más específico que el derecho de asociación en materia política, ya que se refiere expresamente a la prerrogativa de los ciudadanos mexicanos para asociarse libre e individualmente a los partidos políticos y a las agrupaciones políticas, y si bien el derecho de afiliación libre e individual a los partidos podría considerarse como un simple desarrollo del derecho de asociación en materia política, lo cierto es que el derecho de afiliación -en el contexto de un sistema constitucional de partidos como el establecido en el citado artículo 41 constitucional- se ha configurado como un derecho básico con caracteres propios y, por tanto, con mayor especificidad que el derecho de asociación y está garantizado jurisdiccionalmente, mediante el sistema de medios de impugnación en materia electoral previsto en el artículo 41, fracción IV, primer párrafo, in fine, en relación con lo dispuesto en el artículo 99, fracción V, de la Constitución Federal. Además, el derecho de afiliación comprende no sólo la potestad de formar parte de los partidos políticos y de las asociaciones políticas, sino también la prerrogativa de pertenecer a éstos con todos los derechos inherentes a tal pertenencia; en particular, el derecho fundamental de afiliación político-electoral consagrado constitucionalmente faculta a su titular para afiliarse o no libremente a un determinado partido político, conservar o ratificar su afiliación o, incluso, desafiliarse. Del mismo modo, la libertad de afiliación no es un derecho absoluto, ya que su ejercicio 
Las limitaciones al régimen interno de los partidos políticos pueden referirse principalmente a dos cuestiones: la primera, a la observancia de un régimen interno democrático, y la segunda, a la limitación al momento de adoptar acuerdos asociativos referentes al ingreso y expulsión de sus miembros.

Respecto al primer aspecto, sería absurdo pensar que si los partidos políticos son elementos imprescindibles del Estado democrático y en gran medida los instrumentos a través de los cuales la participación política de los ciudadanos se materializa, su funcionamiento interno no sea acorde con los principios democráticos del Estado, por lo que se les exige un régimen interno democrático. Ahora, la democracia interna de los partidos políticos ha de referirse no solo a la elección y rotación de su mesa directiva, sino también al reconocimiento de ciertos derechos de sus miembros dentro del partido. Es por esto que la misma sentencia ya citada del Tribunal Electoral del Poder Judicial de la Federación ha señalado que el derecho de afiliación política "comprende no sólo la potestad de formar parte de los partidos políticos y de las asociaciones políticas, sino también la prerrogativa de pertenecer a éstos con todos los derechos inherentes a tal pertenencia" y si bien el Tribunal señala que "en particular, el derecho fundamental de afiliación político-electoral (...) faculta a su titular para afiliarse o no libremente a un determinado partido político, conservar o ratificar su afiliación o, incluso, desafiliarse", debemos entender que el derecho de afiliación política se extiende a la posibilidad de participar de las decisiones del mismo partido. Así lo entendió incluso nuestra SCJN al señalar que ciertos artículos de la legislación electoral del estado de Jalisco que preveían la observancia de un régimen interno democrático y el respeto de unos derechos de los socios no

está sujeto a una condicionante consistente en que sólo los ciudadanos mexicanos podrán afiliarse libre e individualmente a los partidos políticos. Igualmente, si el ejercicio de la libertad de afiliación se realiza a través de los institutos políticos, debe cumplirse con las formas específicas reguladas por el legislador para permitir su intervención en el proceso electoral. Tercera Época: Juicio para la protección de los derechos político-electorales del ciudadano. SUP-JDC-117/2001.- José Luis Amador Hurtado.30 de enero de 2002.- Mayoría de cinco votos.- Los Magistrados Eloy Fuentes Cerda y Alfonsina Berta Navarro Hidalgo votaron porque se confirmara la resolución impugnada, al considerar que la parte actora no comprobó el hecho fundatorio de sus pretensiones jurídicas, omitiendo, en consecuencia, pronunciarse sobre la cuestión jurídica que aborda la presente tesis. Juicio para la protección de los derechos político-electorales del ciudadano. SUP-JDC-127/2001.- Sandra Rosario Ortiz Noyola.- 30 de enero de 2002.- Mayoría de cinco votos.- Los Magistrados Eloy Fuentes Cerda y Alfonsina Berta Navarro Hidalgo votaron porque se confirmara la resolución impugnada, al considerar que la parte actora no comprobó el hecho fundatorio de sus pretensiones jurídicas, omitiendo, en consecuencia, pronunciarse sobre la cuestión jurídica que aborda la presente tesis. Juicio para la protección de los derechos político-electorales del ciudadano. SUP-JDC-128/2001.- Dora Soledad Jácome Miranda.- 30 de enero de 2002.- Mayoría de cinco votos.- Los Magistrados Eloy Fuentes Cerda y Alfonsina Berta Navarro Hidalgo votaron porque se confirmara la resolución impugnada, al considerar que la parte actora no comprobó el hecho fundatorio de sus pretensiones jurídicas, omitiendo, en consecuencia, pronunciarse sobre la cuestión jurídica que aborda la presente tesis. Sala Superior, tesis S3ELJ 24/2002. 
eran inconstitucionales, pues "la finalidad prevista por la Constitución Política de los Estados Unidos Mexicanos para los partidos políticos, consistente en la promoción de los principios democráticos incluye que éstos deben regir en su interior, pues sólo así permanecen en estrecha comunicación con sus miembros, con lo que se cumplirá el objetivo de permitir que los partidos sean organizaciones de ciudadanos que hagan posible su acceso al poder público; en tal virtud, es necesario que sus estatutos prevean un funcionamiento democrático verdadero, asegurando que cuenten con estructuras y prácticas de participación que tengan el control de sus líderes y la colaboración de sus afiliados en la formación de estos liderazgos, (...) de no existir elementos de certeza en cuanto a sus procedimientos internos y de transparencia en su funcionamiento, así como el establecimiento de garantías para sus afiliados, no cumplirían con la función que constitucionalmente tienen asignada" ${ }^{23}$.

${ }^{23}$ [J]; $9^{a}$ Época; Pleno; S.J.F. y su Gaceta; Tomo XXII, noviembre de 2005; pág. 154. Partidos políticos estatales. Los artículos 56, fracciones II, III y V, y 56 bis de la Ley Electoral del Estado de Jalisco, al prever ciertos requisitos que deben contener los estatutos de aquéllos, son constitucionales. Los citados artículos prevén la obligación de los partidos políticos de incorporar en sus estatutos, el primero, los procedimientos de afiliación individual, libre y pacífica de sus miembros, quienes tendrán el derecho de participar en asambleas y convenciones, de integrar los órganos directivos y estar en condiciones de acceder a la información pública del partido (fracción II); procedimientos democráticos de elección de candidatos a cargos de elección popular y de sus órganos directivos, así como la enumeración de sus funciones, facultades y obligaciones, las que deben ser del conocimiento público (fracción III); así como prever sanciones fundadas y motivadas, impuestas por órganos competentes previamente establecidos y que deben ser proporcionales a la infracción cometida (fracción V); y el segundo, el procedimiento claro para la elección de dirigentes en todos los niveles de organización, y garantizar la certeza, legalidad, independencia, imparcialidad, equidad, objetividad, transparencia y certidumbre: previendo periodos fijos para la duración y renovación de mandos internos y procedimientos para la sustitución de ellos, y estableciendo reglas generales de la elección de los dirigentes y los requisitos mínimos. Ahora bien, los aspectos antes mencionados no representan una intromisión indebida en la vida interna de los partidos, pues la finalidad prevista por la Constitución Política de los Estados Unidos Mexicanos para los partidos políticos, consistente en la promoción de los principios democráticos incluye que éstos deben regir en su interior, pues sólo así permanecen en estrecha comunicación con sus miembros, con lo que se cumplirá el objetivo de permitir que los partidos sean organizaciones de ciudadanos que hagan posible su acceso al poder público; en tal virtud, es necesario que sus estatutos prevean un funcionamiento democrático verdadero, asegurando que cuenten con estructuras y prácticas de participación que tengan el control de sus líderes y la colaboración de sus afiliados en la formación de estos liderazgos, pues de no existir elementos de certeza en cuanto a sus procedimientos internos y de transparencia en su funcionamiento, así como el establecimiento de garantías para sus afiliados, no cumplirían con la función que constitucionalmente tienen asignada. Por otra parte, el hecho de que el artículo 56 bis disponga que, además de lo previsto en el indicado artículo 56, los estatutos deben establecer un procedimiento claro para la elección de los dirigentes en todos los niveles de organización y que, para garantizar la certeza, legalidad, independencia, imparcialidad, equidad, objetividad, transparencia y certidumbre, deben prever reglas respecto de los periodos de duración y renovación de sus mandos internos, así como procedimientos de sustitución de dirigentes electos, aparte de establecer reglas generales para su elección, es una cuestión que tampoco constituye una intromisión en la vida interna de los partidos políticos, por las razones previamente señaladas, en atención a que 
Respecto al segundo aspecto, resulta que la libertad de los partidos políticos para decidir sobre el ingreso o expulsión de sus miembros se ve limitada por el derecho de participación política de los ciudadanos, respecto del cual venimos diciendo que resulta indispensable en un Estado democrático. Es más, los partidos políticos nacen del ejercicio del derecho de asociación política de los individuos, de tal forma que el rechazo de ingreso o la expulsión de un socio a un partido no constituye solo el impedimento de ejercer la libertad de asociación de la persona individualmente considerada (aunque ya señalamos que en el derecho de ingreso no despliega eficacia horizontal alguna), sino que se trata además de la limitación a la persona de su derecho de participación política y de asociación política.

El Tribunal Electoral ha reconocido precisamente que el derecho de afiliación político-electoral reconocido en el art. 41, fr. I párrafo segundo, CPEUM "-en el contexto de un sistema constitucional de partidos como el establecido en el citado artículo 41 constitucional- se ha configurado como un derecho básico con caracteres propios y, por tanto, con mayor especificidad que el derecho de asociación" y esto es así, naturalmente, porque los fines alcanzados mediante la afiliación político-electoral son de mucho mayor trascendencia, o si se quiere, están más directamente relacionados con el Estado democrático.

En España, el Tribunal Supremo se enfrentó a un caso en el que colisionaban, precisamente, el derecho de permanencia de unos miembros frente a la libertad de expulsión de un partido político (STS [Sala de lo Civil] 442/1988 de 12 de mayo) ${ }^{24}$; en este caso, el Tribunal argumentó, entre otras cuestiones, la importancia para los socios de permanecer en la asociación, debido a que

debe garantizarse la promoción del pueblo en la vida democrática de manera efectiva, y que no se dé lugar a la creación de cúpulas en las que siempre recaigan las decisiones y las candidaturas a cargos de elección popular, puesto que tal situación sí sería contraria al espíritu del artículo 41, fracción I, de la Constitución de la República. Pleno. Acción de inconstitucionalidad 13/2005. Partido del Trabajo. 22 de agosto de 2005. Unanimidad de diez votos. Ausente: Guillermo I. Ortiz Mayagoitía. Ponente: Genaro David Góngora Pimentel. Secretarios: Makawi Staines Díaz y Marat Paredes Montiel. El Tribunal Pleno, el dieciocho de octubre en curso, aprobó, con el número 142/2005, la tesis jurisprudencial que antecede. México, Distrito Federal, a dieciocho de octubre de dos mil cinco.

${ }^{24}$ El acuerdo de expulsión vulneró los arts. 24 y 25 CE de los socios porque al tiempo de la comisión de los hechos, el CDS no había procedido a comunicar el texto del Reglamento Disciplinario que se aplicó a los expedientados, que no accedieron al mismo como texto fehaciente, pues no se acreditó que se hubiera efectuado publicación interna del mismo, para conocimiento de todos los integrantes en la referida formación política, lo que implica la vulneración del art. 25.1 de la Constitución (principio de legalidad), en relación al 9.3 de dicho texto, ya que de esta manera los sancionados no llegaron a saber con suficiencia media el alcance de sus actuaciones y que las mismas pudieran ser objeto de sanción establecida. También se vulneró el art. 24.1 CE de los socios expulsados, al entender del Tribunal Supremo, toda vez que el CDS no probó que hubieran sido estos socios los actores de la infracción estatutaria (la cual había consistido en la remisión de una carta interna por cien militantes 
se trataba de un partido político (el "Centro Democrático y Social" [CDS]) y este tipo de asociaciones tienen una finalidad bien precisa y determinada, que es la participación democrática de los ciudadanos en la vida política del país, desempeñando así un papel decisivo en los regímenes políticos democráticos pluralistas, y además, son instrumentos colectivos organizados para poder alcanzar y ejercer el Gobierno por el cauce constitucional de la actuación y la participación electoral ${ }^{25}$.

\subsection{Sindicatos}

Otras asociaciones que ven mermada su libertad de autoorganización debido a su naturaleza son los sindicatos. Los sindicatos son entes que, si bien no participan directamente en la vida política del país, sí lo hacen en su diseño social y económico, convirtiéndose en entes de relevancia -no de naturaleza- pública. Debido a esta relevancia pública es dable exigir de ellos una organización democrática y es dable también limitar en parte su libertad para determinar el ingreso y permanencia de sus miembros.

En su sentencia 552/2005 el Tribunal Superior de Justicia de Madrid reconoció que el derecho de asociación comprende la autoorganización de las asociaciones y que en el ejercicio de este derecho los grupos son libres de establecer en sus estatutos las causas y procedimientos de expulsión de sus socios. No obstante, el Tribunal señaló que debido a que la asociación en cuestión era un sindicato, la expulsión del sindicalista podría producir el efecto inaceptable de que, por mantener uno de los aspectos del contenido del derecho de asociación en su faceta autoorganizativa, se conculcase el derecho también fundamental de todo trabajador a permanecer en el sindicato de su elección con la sola condición de observar los estatutos del mismo ${ }^{26}$. De tal forma que, aun habiendo respetado la asociación todas las garantías del Derecho sancionador y habiendo adoptado el acuerdo de expulsión conforme a sus propios estatutos, el Tribunal entró a conocer del caso más allá de la conducta razonable debido a que la asociación era un sindicato y porque el derecho del socio que resultaba afectado era el de sindicación. Así, el derecho de autoorganización

del CDS a la dirección del partido), lo que también generó una situación de indefinición, agravada por la falta de actividad probatoria a cargo de los instructores del expediente.

${ }^{25}$ Véanse, entre otras, la STS de España de 26 de julio de 1993 y la STC 56/1995, de 6 de marzo de 1995.

${ }^{26}$ Los hechos se refieren a un trabajador que presta sus servicios para Iberia LAE S.A. como comandante y era afiliado al Sindicato Español de Pilotos de Líneas Aéreas (SEPLA). Este trabajador desempeñó sus labores como jefe de día y en el ejercicio de sus funciones instruyó expediente disciplinario por parte de Iberia contra otros tres comandantes que ese día desobedecieron sus órdenes. Por lo que el sindicato decidió entonces abrir un expediente disciplinario en su contra y expulsarlo del grupo. 
del ente cedió en este caso, no frente al derecho de permanencia ni frente a las garantías del Derecho sancionador, sino frente al derecho de sindicación.

De igual forma, en la sentencia de 6 de julio de 2000 (Sala de lo Social) el Tribunal Supremo de España recuerda una vez más que la doctrina sustentada por el Tribunal Constitucional de ese país en su sentencia 218/1988, de 22 de noviembre, no puede ser aplicable en puridad cuando la asociación en cuestión es un sindicato, pues aceptar la expulsión de uno de sus miembros implica la vulneración de su libertad sindical (FD $3^{\circ}$.).

Ocurre entonces que la actuación de los sindicatos concierne no solo a los miembros del grupo, sino a toda una clase y desempeñan una vasta serie de funciones públicas o de relevancia pública, poseyendo un papel institucional destacado como interlocutores del poder político en materias relacionadas con la política económica y social ${ }^{27}$, por lo que la inadmisión o expulsión de una persona de su seno implica no solo la exclusión en sí, sino la imposibilidad de participar activamente en la adopción de decisiones de relevancia pública, tanto en el plano jurídico como en el socioeconómico, y por esto, el derecho de afiliación sindical resulta de especial trascendencia ${ }^{28} y$ debe prevalecer frente a la autonomía organizacional del ente.

\subsection{Asociaciones con posición monopolista o de relevancia en un determinado sector}

Además de los partidos políticos y los sindicatos existen otros tipos asociativos que, debido también a su especial naturaleza o a una condición especial que ostentan, se ven limitados en el ejercicio de su facultad autoorganizativa. Se trata de asociaciones que, si bien son de naturaleza privada, ostentan de hecho o de derecho una posición monopolista o dominante en el campo en el que se desenvuelven, ya sea este económico, social o cultural. Al tener la asociación una de estas condiciones y negar a una persona formar parte de ella le está impidiendo no solo el libre ejercicio de su derecho de asociación, sino el libre ejercicio de otro derecho fundamental, o bien el ejercicio de su libre personalidad ${ }^{29}$.

\footnotetext{
${ }^{27}$ Así lo reconoce MAGRINI (1979), pp. 117-118.

${ }^{28} \mathrm{Al}$ entender de AlONSO OlEA (1985), p. 469. El acto de ingreso en una organización sindical no necesita más requisito que el de presentar la solicitud de ingreso y cumplimentar los trámites y formalidades del procedimiento de admisión que los estatutos estipulen.

${ }^{29}$ En la ya citada STC 218/1988, de 22 de noviembre, en la que el Tribunal Constitucional de España reconoce la libertad de la asociación para expulsar a sus miembros, menciona esta excepción y dice que el caso hubiera sido distinto si: el acuerdo de expulsión hubiese lesionado otros derechos del socio distintos del de asociación, por ejemplo el honor; o si la expulsión del socio, se produjese en
} 
Así, por ejemplo, en la STC 96/1994, de 21 de marzo ${ }^{30}$, el Tribunal Constitucional de España favorece el derecho de permanencia de un socio frente a la asociación a la que pertenecía, porque con la expulsión por parte de la asociación (Sociedad Cooperativa Limitada de Viviendas Molnedo) se afectaba no solo la condición de miembro de la asociación, sino también otros derechos de contenido económico inherentes a su condición de socio, pues tras producirse el acuerdo social de expulsión, el excluido no solo impugnó ante los Tribunales su expulsión, sino también el acuerdo de adjudicación de un bien inmueble y su transmisión a otro socio, por lo que resulta claro que el acuerdo de expulsión, así como el correlativo de la adjudicación del bien a otro miembro, entrañan un perjuicio económico significativo para el expulsado.

En otro caso que se suscitó en España (caso El Palmar ATC 254/2001, de 20 septiembre), cinco mujeres fueron inadmitidas por la asociación "Comunidad de Pescadores de El Palmar", en Valencia, según la asociación por no reunir los requisitos exigidos por las normas de la Comunidad, mismas que consistían en que la candidatura fuera individual (y no colectiva) y que fuera avalada, pero estos requisitos no fueron exigidos a otros aspirantes hombres que en igualdad de circunstancias solicitaron su ingreso en esta asociación y fueron admitidos, razón por la cual, tanto el Juzgado de Primera Instancia núm. 1 de Valencia, como la Audiencia Provincial de esta Comunidad Autónoma, consideraron que el acuerdo de inadmisión obedecía a razones sexistas y vulneraba el derecho de igualdad de las demandantes.

una asociación que, aun siendo privada, ostentase de hecho o de derecho una posición dominante en el campo económico, cultural, social o profesional, de manera que la pertenencia o exclusión de ella supusiese un perjuicio significativo para el particular afectado.

${ }^{30}$ Los hechos versan sobre una asociación, la "Sociedad Cooperativa Limitada de Viviendas Molnedo" que acordó expulsar a uno de sus miembros por haber manifestado expresiones descalificadoras y malsonantes en contra de la Junta Rectora de la asociación. El sancionado promovió un recurso de alzada ante la Asamblea General Extraordinaria de la misma asociación, que confirmó el acuerdo de expulsión. Decisión ante la cual el afectado demanda en menor cuantía a la entidad. El juzgado de Primera Instancia número tres de Santander, que conoce del caso, dicta sentencia declarando nulos los acuerdos de expulsión de la asociación por violar un artículo de sus mismos estatutos. La Cooperativa interpone entonces un recurso de apelación ante la Audiencia Provincial de Burgos, quien en su resolución confirma la sentencia del Juzgado de Santander, considerando que no solo se han violado los estatutos de la asociación, sino que la conducta por la que se está expulsando al socio "no es tan grave". Ante esta resolución, la Cooperativa interpone un recurso de casación ante el Tribunal Supremo, que dicta sentencia desestimatoria confirmando las resoluciones anteriores. Finalmente, el ente promueve recurso de amparo ante el Tribunal Constitucional, sosteniendo en su escrito que se está violando su derecho fundamental de asociación, pues las sentencias del Juzgado de Santander, de la Audiencia Provincial de Burgos y del Tribunal Supremo están valorando la conducta del socio y por tal motivo se vulnera su derecho de autoorganización, pidiendo al Tribunal Constitucional que recuerde la doctrina sustentada en su sentencia 218/1988. 
Cuando el caso llega al Tribunal Constitucional de España, este lo inadmite, pero señala que no puede ampararse en la autonomía de la voluntad de las asociaciones privadas una decisión consistente en negar u obstaculizar el ingreso a una comunidad por razón de sexo, cuando la asociación ocupa una posición privilegiada, al tener reconocida por el poder público la explotación económica exclusiva de un dominio público (las aguas de la Albufera y su riqueza piscícola), de modo que solo se puede ejercer la actividad pesquera en ese lugar si se es miembro de dicha Comunidad. Por tanto, el ingreso a la "Comunidad de Pescadores de El Palmar", en cuanto medio para el acceso al trabajo y al disfrute de una concesión administrativa, no puede regularse por normas que, de forma directa o indirecta, discriminen a las mujeres. Nótese que el Tribunal Constitucional no reconoció el derecho subjetivo de ingreso de las solicitantes a la asociación ni un derecho a la igualdad, sino su derecho a desarrollar una actividad profesional, su derecho a pescar, que solo era posible en esa zona formando parte de la "Comunidad de Pescadores de El Palmar". Aunque el Tribunal no lo afirma expresamente, cabe suponer que, si por el contrario, hubiese existido otra asociación a través de la cual fuese posible alcanzar los mismos fines para los cuales las solicitantes deseaban asociarse, en este caso pescar, o pudiesen crear otra asociación con estos fines, la negativa de ingreso por parte de una asociación no implicaría en sí ninguna violación de derechos fundamentales ${ }^{31}$.

El Tribunal tampoco determinó que la "Comunidad de Pescadores de El Palmar" no tuviese el derecho a negar el ingreso en su seno a las mujeres. Nada tiene de particular, dice F. Rey, que una asociación de Derecho privado consuetudinario, creada en 1238 y constituida históricamente solo por varones, niegue el ingreso de mujeres ${ }^{32}$. Lo que determinó el Tribunal es que al explotar en exclusiva por concesión administrativa un recurso público (la zona de Albufera y su riqueza piscícola), el derecho de autoorganización del ente se veía limitado y por ello debía aceptar en su seno a las mujeres solicitantes.

En conclusión, si una persona no puede realizar una actividad porque esta solo es posible en y a través de una determinada asociación, esta asociación se verá obligada a aceptar y soportar en su seno a esta(s) persona(s) incluso en contra de su voluntad. El mismo razonamiento es aplicable cuando la asociación en cuestión no es la única en un determinado sector, pero ostenta una

\footnotetext{
31 Alfaro Águila-Real (1993), pp. 107 y 108.

32 Hay que admitir, dice Rey MARtínez (1995), p. 67, que fuera del ámbito extenso de las normas imperativas (particularmente en el derecho del trabajo), los particulares pueden relacionarse jurídicamente, en ejercicio de su libertad e intimidad, con otros particulares de modo arbitrario y discriminatorio. Existe una residual facultad para ser sexista (en uno u otro sentido). A ese cada vez más pequeño espacio no llega el Derecho, sino la educación.
} 
posición privilegiada frente a las otras, de tal manera que formar parte de ella repercute considerablemente en la obtención del fin que se persigue. Ahora, si la persona puede obtener los mismos fines y de la misma manera formando parte de otra asociación o creando una nueva, las asociaciones podrán rechazar su ingreso o expulsarlas de su seno, siempre y cuando, en este último caso, se haga conforme a los mismos estatutos ${ }^{33}$.

\section{Conclusiones}

El derecho de asociación es un derecho que se reconoció tardíamente en las Constituciones de los Estados liberales del siglo XIX. En México tuvo lugar hasta la Constitución de 1857 y en 1917 su reconocimiento no cambió en lo absoluto.

Si el reconocimiento constitucional del derecho fue tardío, su dimensión objetiva, es decir, el reconocimiento de su autonomía organizativa lo fue aún más. Ni siquiera el constitucionalismo de la segunda posguerra llegó a reconocer que el ámbito de protección que dispensa la libertad asociativa comprende a la misma asociación que nace del ejercicio del derecho individual. No obstante, este reconocimiento se ha dado a golpe de jurisprudencia hasta considerarse doctrina consolidada, de tal forma que cualquier intervención indebida por parte de terceros en la libertad autoorganizativa de las asociaciones se considera como una violación al mismo derecho de asociación.

El hecho de que las asociaciones se encuentran constitucionalmente protegidas y puedan actuar libremente no significa que puedan actuar sin observar límite alguno. Como el ejercicio de todos los derechos fundamentales, la dimensión colectiva del derecho fundamental de asociación ha de observar unos límites y algunos de estos, además de la observancia del ordenamiento jurídico, vienen determinados por el mismo tipo asociativo del que se trate.

Los partidos políticos, por ejemplo, si bien son asociaciones privadas, son entes de relevancia pública que participan de la vida política del país y hacen posible la participación del ciudadano común en las decisiones del Estado. Y es precisamente por su relevancia pública y carácter fundamental en el mantenimiento del Estado constitucional y democrático de derecho que los partidos

\footnotetext{
${ }^{33}$ Este caso, como muchos otros de las relaciones intraasociativas son manifestaciones claras de la eficacia horizontal de los derechos fundamentales. Esta teoría tiene sus orígenes en la Alemania de la segunda posguerra, del intelecto de H.C. Nipperday y su detractor D.C. Dürig. En términos resumidos, la teoría propugna que si bien los derechos nacieron como límites al poder del Estado, esto es con una eficacia vertical, al entender a estos derechos como principios y valores de todo el ordenamiento jurídico surten sus efectos no solo frente al poder estatal, sino también a los poderes fácticos económicos y sociales que detentan también las personas privadas, y en consecuencia deben verse vinculadas por estas. Confróntese Anzures (2010), pp. 3-51. "La eficacia horizontal de los derechos fundamentales".
} 
políticos encuentran ciertas limitantes en el ejercicio de su autonomía organizativa, como es la observancia de un régimen interno democrático y la facultad también restringida para decidir sobre el ingreso o salida de sus miembros.

Los sindicatos son otros entes que si bien no participan directamente en la vida política del país, sí lo hacen en la vida social y económica, además de que la pertenencia de cualquier persona en estas asociaciones constituye el ejercicio del derecho fundamental de sindicación. Así, los sindicatos al ser tan indispensables en la vida económica y social, constituyen la forma de ejercer un derecho fundamental en sí mismo, además del propio derecho de asociación, lo que constituye una límite más, o extra, a su facultad de autoorganización.

Por lo demás, pueden existir asociaciones que sin tener una relevancia pública, ya en el sentido político o socioeconómico, detentan una posición monopolista o de relevancia en un determinado sector, y aunque se trate de una asociación meramente privada su condición preponderante le hace también limitar su facultad autoorganizativa.

En conclusión, si bien el haz de protección del derecho fundamental de asociación comprende la autoorganización de la misma asociación, esta se verá limitada por el tipo asociativo en cuestión.

\section{Bibliografía CitADA}

Alfaro Águila-Real, Jesús (1993): "Autonomía privada y derechos fundamentales", en: Anuario de Derecho Civil (Vol. 46, № 1), pp. 57-122.

Alonso Olea, Manuel (1985): Derecho del Trabajo, $9^{a}$ ed. (Madrid, Servicio de Publicaciones de la Universidad Complutense).

Anzures Gurría, José Juan (2014): La protección constitucional de las asociaciones. Sobre la dimensión colectiva del derecho de asociación (Madrid, Centro de Estudios Políticos y Constitucionales).

De la Cueva, Mario (2002): El nuevo derecho mexicano del trabajo, $12^{\text {a }}$ ed. (México, Porrúa), tomo II.

Fernández Segado, Francisco (1986): Las constituciones históricas españolas: un análisis histórico-jurídico (Madrid, Civitas).

GaStROPH, Claus (1970): Die politischen Vereinigungen. Inhalt und Grenzen der Vereinigungsfreiheit des Art. 9 des Grundgesetzes im politischen Bereich in der Verfassungsstruktur der Bundesrepublik Deutschland (Berlín, Dunker \& Humblot).

Gómez montoro, Ángel José (2004): Asociación, Constitución, Ley. Sobre el contenido constitucional del derecho de asociación (Madrid, Tribunal Constitucional-Centro de Estudios Políticos y Constitucionales). 
MagrinI, Sergio (1970): II sindacato come soggetto, en indagine sul sindicato, a cura dell'ISLE, (Milano, Giuffre).

Merten, Detlef (2009): "Vereinsfreiheit", en: Isensee, Josef y KirchHof, Paul, Handbuch des Staatsrechts der Bundesrepublik Deutschland (C.F. Müller Verlag, Heidelberg).

Pelayo Olmedo, José Daniel (2007): "El derecho de asociación en la historia constitucional española, con particular referencia a las leyes de 1887 y 1964", en: Historia Constitucional (№ 8), pp. 95-122.

Rey MARTínez, Fernando (1995): El derecho fundamental a no ser discriminado por razón de sexo (Madrid, McGraw-Hill).

SCHMidT, Thomas (1983): Die Freiheit verfassungswidriger Parteien und Vereinigungen. Zur Schrankenlehre im Rahmen von Art. 21 Abs. 2 und Art. 9 Abs. 2 GG (Berlín, Dunker und Humbolt).

Velloso Jiménez, Luisa (1982): "Los orígenes constitucionales del derecho de asociación en España (1868-1923)", en: Anuario de la Facultad de Derecho $\left(\mathrm{N}^{\circ} 1\right)$. 